\title{
3D Finite Element Study on Incomplete Osseointegration: Locator Attachment versus Ball Attachment
}

\author{
Hisham S. ElGabry ${ }^{1 *}$, Salah A. Yousief ${ }^{2}$, Amal H. Moubarak ${ }^{3}$, Iman A. Eltaftazani ${ }^{4}$, Mohamad El-Anwar ${ }^{5}$, Mohamed M. El-Zawahry ${ }^{1}$ \\ ${ }^{1}$ Department of Prosthodontics, National Research Centre, MSA University, $6^{\text {th }}$ of October City, Egypt; ${ }^{2}$ Department of \\ Restorative and Prosthetic, College of Dentistry, Dar Al Uloom University, Riyadh, Saudi Arabia; ${ }^{3}$ Department of Removable \\ Prosthodontics, Ain Shams University, Cairo, Egypt; ${ }^{4}$ Department of Removable Prosthodontics, Misr International University, \\ Cairo, Egypt; ${ }^{5}$ Deaprtment of Mechanical Engineering, National Research Centre, Cairo, Egypt.
}

Edited by: Aleksandar lliev Citation: EIGabry HS, Yousief SA, Moubarak AH Eltaftazani IA, EI-Anwar M, El-Zawahry MM. 3D Finite Element Study on Incomplete Osseointegration: Locato Attachment versus Ball Attachment. Open Access Maced J Med Sci. 2021 Feb 28; 9(D):24-28.
https://doi.org/10.3889/oamjms.2021.5680 Keywords: Finite Element Analysis; Locator Attachment; Keywords: Finite Element Analysis; Locator Attachment
Ball and Socket Attachment; Incomplete Osseointegration ${ }^{*}$ Correspondence: Mr. Hisham Samir ElGabry,
Ball and Socket Attachment; Incomplete Osseointegration th of Prosthodontics, National Research Centre, MSA University, 83, Pyramids Street, Cairo, Egypt. E-mail: hishamelgabry@live.com Received: 12-Jan-202 Revised: 14-Feb-202 Copyright: $\odot$ Accepted: $19-\mathrm{Feb}-2021$ Copyright: @ 2021 Amal H. Moubarak Mubarak, Iman A. Eltaftazani, Mohamad, El-Anwar, Moubarak, In A. Elatazani, Mohamad El-Anwar, Funding: This research did not receive any financial Competing Interest: The authors have declared that no competing interest exists Open Access: This is an open-access article distributed under the terms of the Creative Commons AttributionAbstract

BACKGROUND: Incomplete implant osseointegration may affect the choice of the type of attachment to ensure less amount of bone resorption, periods of maintenance, and longer implant/attachment life-time.

AIM: The aim of this study was to evaluate, using 3D FE analysis (FEA), the influence of two different types of attachments on the rate of bone resorption, need for maintenance and implant/attachment life time in cases of unpredictable osseointegration in various bone types and using different implant angulations.

METHODS: Six finite element models were prepared; three for the locator attachment while the other three for the ball attachment. Each of the three models simulates vertical implant and inclined implants by $10^{\circ}$ and $20^{\circ}$ degrees. Frictional contact between implant and cortical bone simulated the incomplete osseointegration scenario.

RESULTS: Non-linear static analysis results showed that locator attachment and its cap may have longer time life in comparison with the ball attachment and its cap.

CONCLUSIONS: Both attachments were safe for cortical and spongy bone, while the cortical bone receives less Von Mises stress by up to $33 \%$ with the increased implant angulation.

\section{Introduction}

As life spans lengthen, teeth lose becomes significant for a wide patients' population. Older patient's treatment, especially those with disabilities, becomes a challenge. The primary goal for such patients' treatment is to restore their condition to an acceptable level of satisfactory esthetics and function. The main reason that mandibular dentures show functional problems is because of compromised denture foundation area and thus the poor retention. And since complete dentures support and retention depend mainly on the residual alveolar ridge, it is the mandibular dentures that suffer the most.

Nevertheless, mandibular overdentures can be used as the unique treatment of choice for compromised completely edentulous patients; where overdenture retention is gained by the implant supporting retentive attachments. Furthermore, the use of a fewer implants' number that provides good support and retention is also more favorable for such patients [1].

Huang et al. (2008) studied the effects of implant surface roughness and stiffness of grafted bone on an immediately loaded implant using finite element (FE) models and three conditions of implant-bone interfaces. It was concluded that bone stresses increased by $57 \%$, with 0.3 frictional coefficient with the implant, in comparison to complete osseointegration. It was concluded that bone stresses increased by $57 \%$, with 0.3 frictional coefficient with the implant, in comparison to complete osseointegration and that raising the grafted bone stiffness, diminished the bone stress by about $10 \%$ in both the immediately loaded implants and the osseointegrated ones. It was also noted that increasing graft stiffness and implant surface roughness reduced the sliding at the implant-bone interface which may improve the implant long-term stability and survival rate [2].

Furthermore, adequate available horizontal and vertical bone dimensions are considered as an essential prerequisite for successful and predictable implant osseointegration. However, bone resorption usually continuous following teeth extraction. Thus, implant placement might result in crestal bone dehiscence with exposed implants threads. Consequently, an esthetic problem is to be expected, especially in the anterior region which may be further complicated with periimplantitis or peri-implant mucositis [3]. 
The purpose of this study was to evaluate, using 3D FE analysis (FEA), the influence of two different types of attachments on the rate of bone resorption, need for maintenance and implant/attachment life time in cases of unpredictable osseointegration in various bone types and using different implant angulations.

\section{Materials and Methods}

\section{Design of experiment}

This comparative study was performed for comparing between locator and ball attachments joined to a vertical and inclined implant in two angulations; $10^{\circ}$ and $20^{\circ}$, subjected to vertical load of $100 \mathrm{~N}$ placed on the cap center point of its top surface.

\section{Geometry and modeling}

The geometrical models were created manually using commercial 3-D modeling package, Inventor version 8 (Autodesk Inc., San Rafael, CA, USA). The system analyzed in this investigation consisted of the commonly available root form threaded titanium dental implant (Zimmer Dental Inc., USA) with ball attachment of $6.0 \mathrm{~mm}$ height or locator attachment $6.5 \mathrm{~mm}$ height (Zest Anchors, Escondido, CA). The root form dental implant had a nominal diameter of $3.7 \mathrm{~mm}$, a length of $13 \mathrm{~mm}$. and the shape of internal hex with a hex width $3.5 \mathrm{~mm}$ (Figure 1a and b).

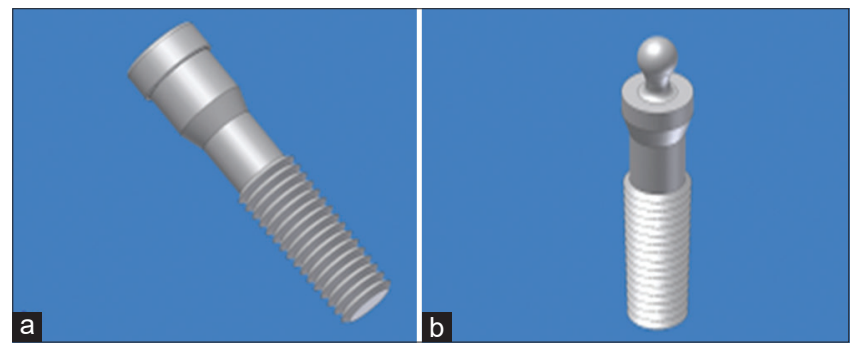

Figure 1: Geometrical model of the implant with (a) locator abutment and (b) ball abutment

The model was designed that the implant was placed in two coaxial cylinders; the outer layer represented cortical bone of $1 \mathrm{~mm}$ thickness, $16 \mathrm{~mm}$ diameter, and $24 \mathrm{~mm}$ height. The inner cylinder represented the cancellous bone of $14 \mathrm{~mm}$ diameter and $22 \mathrm{~mm}$ height. It was assumed that incomplete osseointegration was present between implants and bone. Thus, it was expected to have relative motion (sliding) between the implant neck and cortical bone [4], [5], [6], [7].

\section{Material properties}

Values of material properties were based on previously published data and listed in Table 1. All materials were assumed to be isotropic, homogenous, and linearly elastic [8], [9].
Table 1: Material properties of assembly components

\begin{tabular}{lll}
\hline Material & Young's modulus [MPa] & Poisson's \\
\hline Cortical & 13,700 & 0.30 \\
Cancellous & 1370 & 0.30 \\
Implant/abutment (Titanium) & 110,000 & 0.35 \\
Nylon ring & 350 & 0.40 \\
\hline
\end{tabular}

\section{Meshing}

After construction of all of the components of the model, they were exported to the ANSYS APDL version 12 ${ }^{\circledR}$ (ANSYS Inc., Canonsburg, PA, USA) as IGES files and were assembled together to obtain a FE model after set of Boolean operations between the imported components. The meshing element was 8-nodes Brick element (SOLID 185), which has three degrees of freedom (translations in the global directions). Frictional contact was defined by the elements CONTACT 174 and TARGET 170 as surface to surface contact with friction coefficient of 0.4 between cortical bone and implant neck (Figure 2).

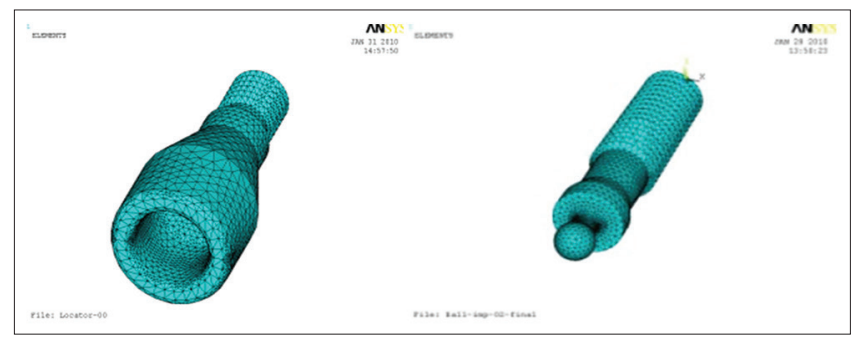

Figure 2: Meshed models' components

Table 2 lists number of nodes and elements of the models of the meshed models [10].

Table 2: Models meshing details of ball and locator abutments

\begin{tabular}{llllll}
\hline Item & \multicolumn{2}{l}{ Locator attachment } & & \multicolumn{2}{l}{ Ball attachment } \\
\cline { 2 - 3 } & Nodes & Elements & & Nodes & Elements \\
\hline Cortical bone & 1375 & 4233 & & 1790 & 28,346 \\
Cancellous bone & 6280 & 28,737 & & 68,571 & 95,829 \\
Implant abutment & 11,998 & 57,829 & & 36,071 & 4180 \\
Resilient cap & 1865 & 8842 & & 2242 & 63,303 \\
Total & 18,511 & 99,641 & & 49,597 & 63,303 \\
\hline
\end{tabular}

\section{Application of load and boundary conditions}

A vertical load of $100 \mathrm{~N}$ was applied at the central node of the top surface of either attachment's cap. The lowest area of cortical bone (outer cylinder base) was considered as a fixed in all directions as a boundary condition.

\section{FE calculations}

Non-linear static analysis of the models was performed on a personal computer (Intel Core ${ }^{\mathrm{TM}} 2$ Duo, processor $2.8 \mathrm{GHz}, 3.0 \mathrm{~GB}$ RAM) that each run takes about $6.5 \mathrm{~h}$.

\section{Results}

Demonstration of cap results to indicate cap life time $=$ longer maintenance periods . 
As presented in Table 3, ball attachment nylon cap is suffering with inclined implant. Its Von Mises stress is close to its yield point in case of implant angulation of 10 and exceed the yield stress with implant angulation of 20. Locator attachment nylon cap is safe and can survive with increasing implant angulation up to $20^{\circ}$.

\section{Demonstration of implant results to} indicate implant life time

As presented in Table 4, ball attachment is generally safe that its angulation of $20^{\circ}$ showed maximum Von Mises stress of order $146 \mathrm{MPa}$, which is far from its material yield stress and below its endurance limit. Locator attachment is extremely safe, and its Von Mises stresses with different implant angulations were less than ball attachment.

As presented in Table 5, cancellous bone is insensitive to changing the implant attachment (ball or locator). Its' stresses and deformation values are indicating negligible differences and far below critical points.

As presented in Table 6, both attachments are showing acceptable effect on cortical bone (did

Table 3: Von Mises stress on nylon caps

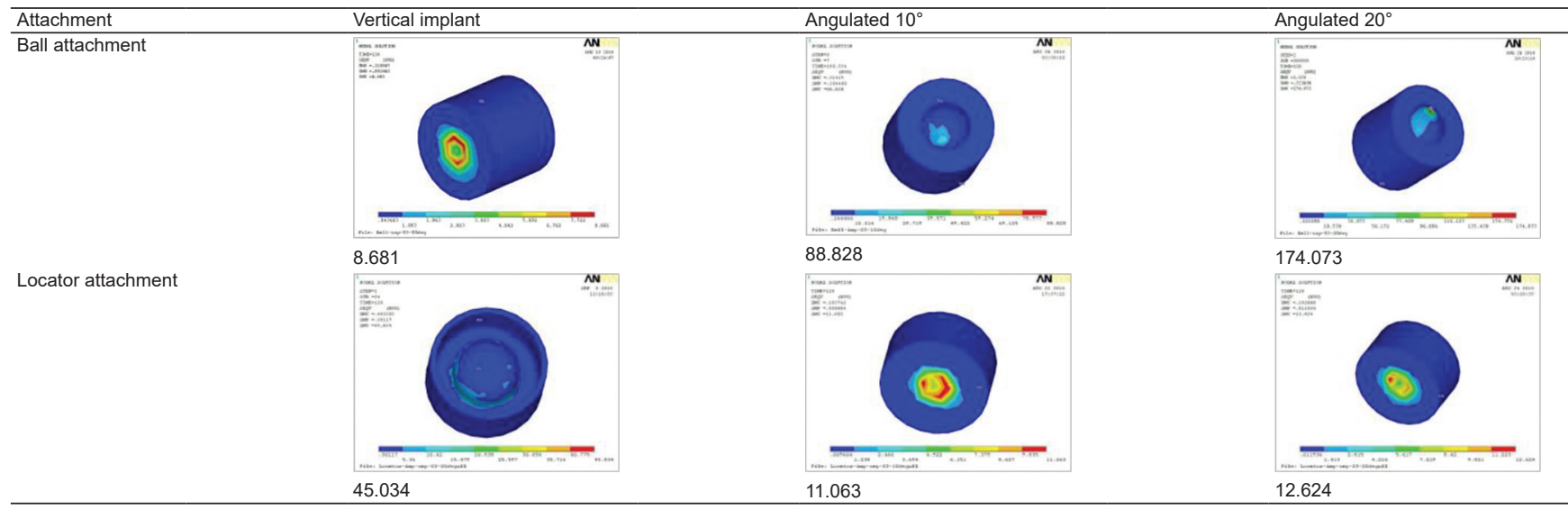

Table 4: Von Mises stress on implant/abutment

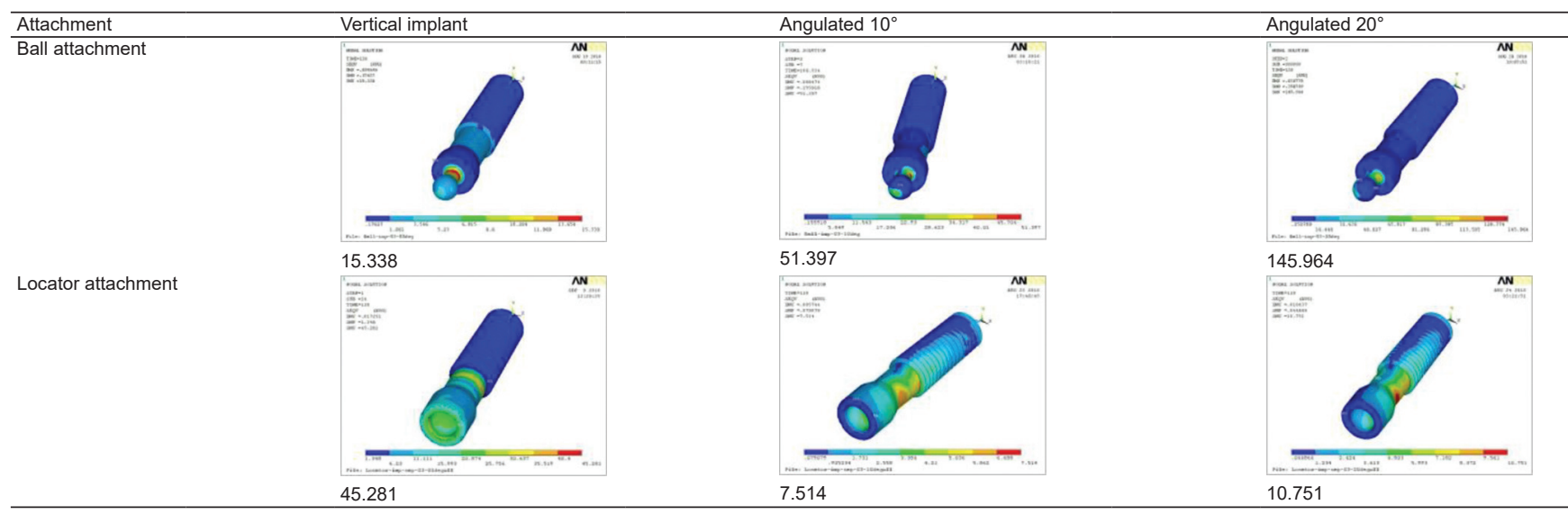

Table 5: Von Mises stress on cancellous bone

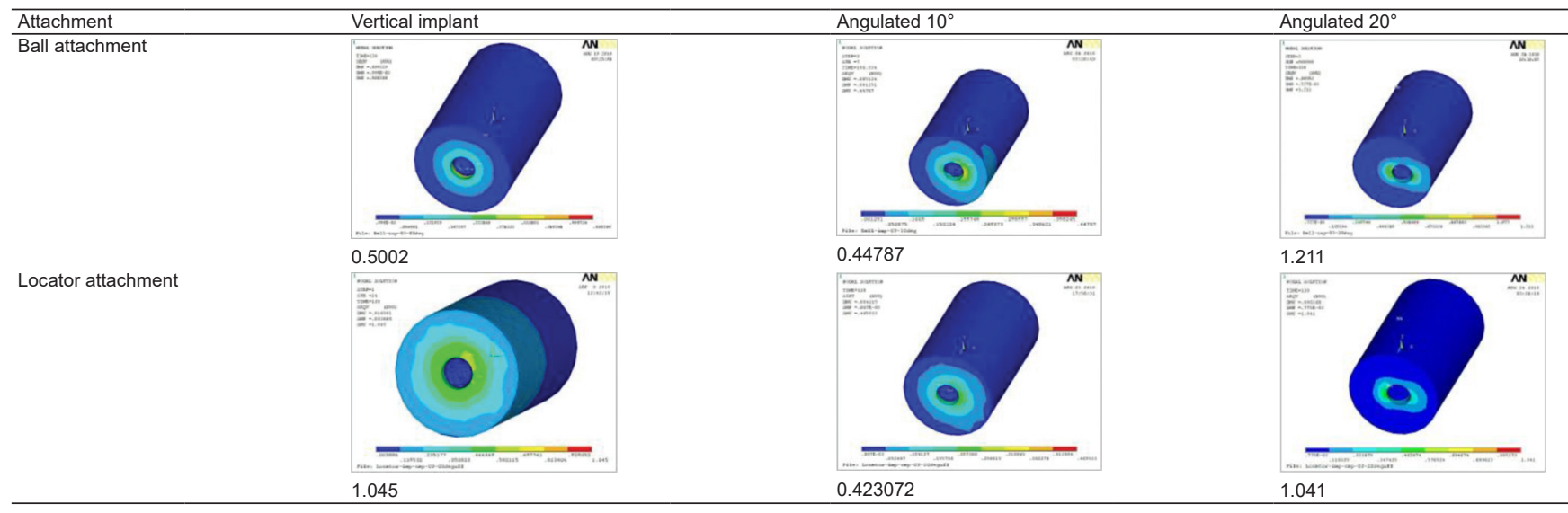


Table 6: Von Mises stress on cortical bone

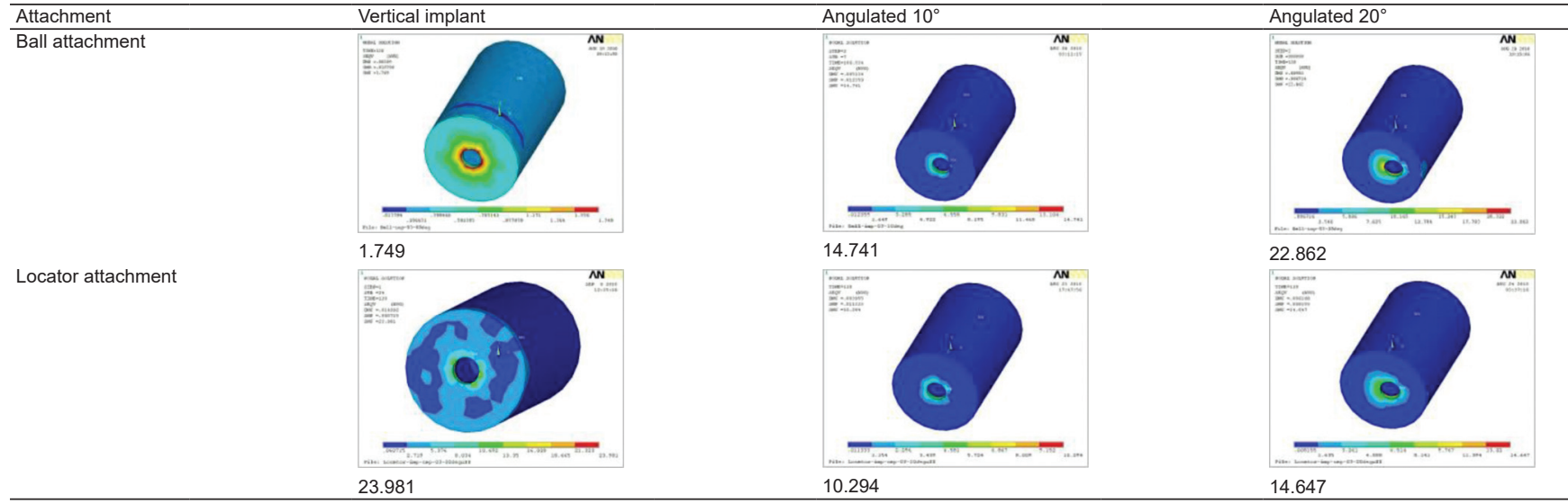

not exceed $25 \mathrm{MPa}$ ). Ball attachment showed superior behavior with vertical implants. On the other hand, inclined implants are recommended to be used with locator attachments that stresses generated on cortical bone are of order $33 \%$ less with using locator attachment.

\section{Discussion}

Design and analysis of threaded dental implants are a very interesting research topic. Threadrelated parameters are of great importance due to their effects on stress and strain distribution [11].

It has been well recognized for decades that neither implant nor bone should be stressed beyond a limited range for physiologic homeostasis as overloading usually results in excessive bone resorption or even implant's fracture. On the other hand, no load over the bone can induce atrophy or subsequent bone loss [12].

According to literature, two implant-supported mandibular overdentures were considered to be the gold standard for edentulous patients. Studies have shown that differences do exist and are evident in the way stresses are being transferred to the surrounding bone not only in toothsupported overdentures but also in the implant-supported overdentures. The load at the bone-implant interface depends mainly on implant geometry, loading type, material properties of both implant and prosthesis, bone nature at implant interface, and bone quality/quantity [1], [13], [14].

Meanwhile, various types of attachments have been used with implant-supported overdentures, the most commonly used are the ball attachment, bar attachment, and the magnet attachment. In vitro and in vivo studies show that the ball and O-ring attachment transferred the least stresses to the implants when compared to the bar clip attachment.

It has been reported that the retentive properties of magnet attachment in addition to its low retentive energy could assist in abutments preservation. On the other hand, ball attachments are considered the simplest type of attachment of all times for various clinical overdenture situations; being untimely resilient, whereas the special ball attachment design sometimes influences the amount of its free movement thus, limiting its resiliency. As for the magnetic attachment, alloy corrosion and wear are to be considered regarding its retentive capability. Furthermore, comparative studies on the retentive force of ball and magnetic attachment reported that the magnetic attachment offers the weakest retentive attachment system [15], [16].

It is to be mentioned that the most important aspect supposed to affect implant success or failure is the manner in which stresses are transferred from the implant to the bone. Thus, it is of utmost importance that neither the implant nor the bone to be stressed beyond their fatigue capacity after loading. Any type of micromotion that can produce either bone lose or implant failure should be avoided as much as possible. Proper implant-bone contact means that under any type of loading, it moves as single unit without bone lose or the implant loosening and with the possibility of transferring stress to all parts of the implant-bone interface [17], [12].

Implants' surrounding stresses are of great importance that several methods have been reported to minimize these stresses. Accordingly, the present study results offer good suggestions for placing different types of dental implant attachments where stresses over prosthodontic components and bone could be better tolerated and distributed [12].

Furthermore, dental implant systems biomechanical performance, the way of load distribution, and the different stresses located at the bone-implant interface have been extensively studied using FEA. It has be reported frequently that the variables that affect greatly the load transfer at the bone-implant interface in addition to the loading type are, the properties of the prosthesis material, implant length and diameter, implant surface, nature of the bone-implant interface, and the quantity and quality of surrounding bone [12], [18].

The data reported from the present study underline which type of dental implant attachment supporting overdenture prosthesis is better to be used in cases of unpredictable osseointegration in different bone types and various implant angulations. 


\section{Conclusions}

Within the limitations of this study, the following conclusions were drawn:

1. Both attachment types showed acceptable effect on cortical bone. Ball attachment showed superior behavior with vertical implants

2. Ball attachment is generally preferred in case of vertical implant fixation. On the other hand, locator attachment is much better in case of angulated implant fixation

3. The greatest stress concentrations were noted at the cortical bone crest in all the models irrespective of the loading conditions. This conclusion was made based on sensitivity analysis in FEA.

\section{Ethical Approval}

This research does not require ethical approval and followed the Helsinki Declaration.

\section{References}

1. John J, Rangarajan V, Savadi R, Kumar S, Kumar PS. A finite element analysis of stress distribution in the bone, around the implant supporting a mandibular overdenture with Ball/O Ring and magnetic attachment. J Indian Prosthodont Soc. 2012;12(1):37-44. https://doi.org/10.1007/s13191-012-0114-0 PMid:23450217

2. Huang HL, Fuh LJ, Hsu JT, Tu MG, Shen YW, Wu CL. Effects of implant surface roughness and stiffness of grafted bone on an immediately loaded maxillary implant: A 3D numerical analysis. J Oral Rehabi. 2008;35(4):283-90. https://doi. org/10.1111/j.1365-2842.2007.01817.x

PMid:18321264

3. Hudieb MI, Wakabayashi N, Abu-Hammad OA, Kasugai S. Biomechanical effect of an exposed dental implant's first thread: A three-dimensional finite element analysis study. Med Sci Monit. 2019;25:3933-40. https://doi.org/10.12659/msm.913186 PMid:31131833

4. Eltaftazani I, Moubarak A, El-Anwar M. Locator attachment versus ball attachment: 3-Dimensional finite element study. Egypt Dent J. 2011;57(2):73-85.

5. AbdelAzim A, Zaki A, El-Anwar M. Restoration of a largediameter single-implant molar versus two conventional implants, CAD / CAM The international digital dentistry magazine, French edition is a magazine of the dental tribune international group and will be published annually with one issue per quarter. Dent Tribune. 2013;4(3):20-5.

6. El-Anwar M, El-Zawahry M, El-Mofty M. Load transfer on dental implants and surrounding bones. Aust J Basic Appl Sci. 2012;6(3):551-60.

7. El-Anwar M, El-Mofty M, Ahmed A, El-Sheikh S, El-Zawahry M.
The effect of using different crown and implant materials on bone stress distribution: A finite element study. Egypt J Oral Maxillofac Surg. 2014;5(2):58-64. https://doi.org/10.1097/01. omx.0000444266.10130.4c

8. Meijer HJ, Starmans FJ, Steen WH, Bosman F. Location of implants in the interforaminal region of the mandible and the consequences for the design of the superstructure. J Oral Rehabil. 1994;21(1):47-56. https://doi.org/10.1111/j.1365-2842.1994. tb01123.x

PMid:8133388

9. Huang $\mathrm{HL}$, Chang $\mathrm{CH}$, Hsu JT, Fallgatter AM, Ko CC. Comparison of implant body designs and threaded designs of dental implants: A 3-dimensional finite element analysis. Int J oral Maxillofac Implants. 2007;22(4):551-62. https://doi. org/10.1111/j.1600-0501.2005.01124.x PMid:17929515

10. El-Anwar M. Simple technique to build complex 3D solid models. In: $19^{\text {th }}$ International Conference on Computer Theory and Applications (ICCTA 2009), Alexandria, Egypt; 2009.

11. Geramizadeh $M$, Katoozian $H$, Amid R, Kadkhodazadeh M. Three-dimensional optimization and sensitivity analysis of dental implant thread parameters using finite element analysis. J Korean Assoc Oral Maxillofac Surg. 2018;44(2):59-65. https:// doi.org/10.5125/jkaoms.2018.44.2.59

PMid:29732310

12. Cicciù $M$, Cervino $G$, Milone $D$, Risitano G. FEM Investigation of the stress distribution over mandibular bone due to screwed over-denture positioned on dental implants. Materials (Basel). 2018;11(9):1512. https://doi.org/10.3390/ma11091512 PMid:30142897

13. El-Anwar M, Saleh M, Omar W. Stresses distribution of two different attachment designs under implant supported overdenture-a finite element study. In: Proceedings of Association of Egyptian American Scholars Conference-Cairo University, Cairo, Egypt; 2012.

14. Satpathy S, Babu SC, Shetty S, Raj B. Stress distribution patterns of implant supported overdentures-analog versus finite element analysis: A comparative in vitro study. J Indian Prosthodont Soc. 2015;15(3):250-6. https://doi. org/10.4103/0972-4052.165324 PMid:26929521

15. Chang Y, Tambe A, Maeda Y, Wada M, Gonda T. Finite element analysis of dental implants with validation: To what extent can we expect the model to predict biological phenomena? A literature review and proposal for classification of a validation process. Int J Implant Dent. 2018;4(1):7.https://doi.org/10.1186/ s40729-018-0119-5

PMid:29516219

16. Caldas RA, Pfeifer CS, Bacchi A, Dos Santos MB Reginato VF, Consani RL. Implant inclination and horizontal misfit in metallic bar framework of overdentures: Analysis by 3D-FEA method. Braz Dent J. 2018;29(2):166-72. https://doi. org/10.1590/0103-6440201801672

17. Ozan O, Ramoglu S. Effect of implant height differences on different attachment types and peri-implant bone in mandibular two-implant overdentures: 3D Finite element study. J Oral Implantol. 2015;41(3):e50-9. https://doi.org/10.1563/ aaid-joi-d-13-00239

PMid:24471769

18. Cervino G, Romeo U, Lauritano F, Bramanti E, Fiorillo L, D'Amico $C$, et al. Fem and von mises analysis of OSSTEM ${ }^{\circledR}$ dental implant structural components: Evaluation of different direction dynamic loads. Open Dent J. 2018;12:219-29. https:// doi.org/10.2174/1874210601812010219

PMid:29682092 